\title{
Minireview
}

\section{Multiple roles of mucins in pancreatic cancer, a lethal and challenging malignancy}

\author{
N Moniaux', M Andrianifahanana', RE Brand ${ }^{2}$ and SK Batra ${ }^{* 1,2}$ \\ 'Department of Biochemistry and Molecular Biology, Eppley Institute for Research in Cancer and Allied Diseases, University of Nebraska Medical Center, \\ Omaha NE 68198, USA; ${ }^{2}$ Evanston Northwestern Healthcare, Evanston, IL 6020I, USA
}

Mucins are members of an expanding family of large multifunctional glycoproteins. Pancreatic mucins have important biological functions, including the protection, lubrication, and moisturisation of the surfaces of epithelial tissues lining ductal structures within the pancreas. Several lines of evidence support the notion that deregulated mucin production is a hallmark of inflammatory and neoplastic disorders of the pancreas. Herein, we discuss the factors that contribute to the lethality of pancreatic cancer as well as the key role played by mucins, particularly MUCI and MUC4, in the development and progression of the disease. Aspects pertaining to the aberrant expression and glycosylation of mucins are discussed, with special emphasis on their potential impact on the design and implementation of adequate diagnostic and therapeutic strategies for combating this lethal malignancy.

British Journal of Cancer (2004) 91, 1633- 1638. doi:I0.1038/sj.bjc.6602I63 www.bjcancer.com

Published online 19 October 2004

(C) 2004 Cancer Research UK

Keywords: mucin; $\mathrm{MUCl}$; MUC4; pancreatic cancer; diagnosis; therapy

Mucins are a large family of glycoproteins that, either directly or indirectly, act to maintain the integrity, lubricate and protect the epithelial surfaces within the human body. In general, mucins exhibit a defined spatial and temporal pattern of expression throughout the development of an organism (Braga et al, 1992). In numerous pancreatic pathologic situations, however, their expression is deregulated, and their aberrant expression is often associated with a poor prognosis (Braga et al, 1992; Reis et al, 1999; Andrianifahanana et al, 2001). This paper will review the role played by mucins, particularly MUC1 and MUC4, in the development and progression of pancreatic cancer (PC) and will highlight key aspects that may account for the lethality of this malignancy.

\section{THE MUCIN FAMILY}

For long, mucins were known as high molecular weight $O$ glycoproteins, secreted by specialised epithelial cells. As main contributors to the rheologic properties of the mucus, mucins were thought to have the sole functions of protecting and lubricating epithelial surfaces. Following the development of molecular biological methods, however, a wide range of mucin structures became available and gave rise to a plethora of biochemical definitions of mucins. As the diversity of mucin structures grew in importance, a variety of functions were assigned accordingly. At present, a total of 21 genes have received the appellation MUC: MUC1-2, MUC3A, MUC3B, MUC4, MUC5AC, MUC5B, MUC6-13,

* Correspondence: SK Batra, Department of Biochemistry and Molecular Biology, Eppley Institute for Research in Cancer and Allied Diseases, University of Nebraska Medical Center, 985870 Nebraska Medical Center, Omaha, NE 68198-5870, USA; E-mail: sbatra@unmc.edu Received 22 June 2004; revised 27 July 2004; accepted 29 July 2004; published online 19 October 2004
MUC15-20 (Moniaux et al, 2001; Hollingsworth and Swanson, 2004; Andrianifahanana et al, 2004). In all, 14 of these code for proteins presenting the five common features of a mucin, including (I) secretion into the mucus layer, (II) high molecular weight $O$-glycoprotein, (III) presence of a tandem repeat array encoded by a unique and centrally positioned large exon, (IV) presence of a predicted peptide domain containing a high percentage of serine and threonine residues, and (V) a complex pattern of mRNA expression.

The 14 classical mucins can be further grouped into two subfamilies: secreted and membrane-bound. Typically, secreted mucins are expressed exclusively by specialised epithelial cells, are secreted in the mucus, and display a restricted expression pattern within the human body. Among these, MUC2, MUC5AC, MUC5B, and MUC6 are expressed in the pancreas either under normal physiologic or tumoral conditions. These four mucins, referred to as the gel-forming mucins, have a common architecture with a high level of similarity to the pro-von Willebrand factor. The secreted mucins whose genomic sequences have been fully characterised are known to harbour five D domains, thus called because of their homology to the D domains of the von Willebrand factor. The D1, D2, D', and D3 domains are located in the $\mathrm{N}$ terminal region and the $\mathrm{D} 4$ and $\mathrm{CK}$ (Cystine Knot) domains in the C-terminal region. Moreover, cystein-rich domains (called Cys) alternate with the tandem repeat sequences in a variable number depending on the mucin (for a review, see Moniaux et al, 2001). The gel-forming mucins form intermolecular disulphide-linked multimers. Mucin subunits initially form homodimers through the disulphide bonds from their CK domains and subsequently heterooligomerise through the $\mathrm{D}$ domains from their N-terminal extremities (Van Klinken et al, 1998). The Cys domains are believed to bring another level of complexity to the oligomerisation process via intermolecular disulphide bond formation. As the composition of gel-forming mucins differs among tissues 
according to the types of mucins expressed, the rheologic properties of the mucus will be different and specific.

The membrane-bound mucins are composed of MUC1, MUC3A, MUC3B, MUC4, MUC11, MUC12, MUC16, and MUC17. For the purpose of clarity, MUC11 and MUC12 will be hereon referred to as MUC11-12, and MUC3A and MUC3B as MUC3A-B. It is not fully understood at this point whether these genes are related to unique or independent loci. The membrane-bound mucins share a common property of being expressed by distinct cellular types, epithelial or other. Implanted at the apical surface of epithelial cells, they are also secreted and, therefore, take part in mucus formation. As compared to the secreted mucins, they present a wider and more complex expression pattern. Indeed, they can be expressed in four distinct forms: membrane-anchored, soluble (proteolytic cleavage of the membrane-bound form), secreted (alternatively spliced variants), and lacking the tandem repeat array (alternatively spliced variants) (Wreschner et al, 1990; Choudhury et al, 2000; Moniaux et al, 2000). The ratio of one form to another appears to be tissue-specific and associated to the physiologic conditions (normal or tumoral). In addition to the proteolytic cleavage that releases the secreted forms from the cell surface, mucin precursors from this group, MUC1 and MUC4, possess a second proteolytic cleavage site that processes the precursor into a mature heterodimer. This second cleavage is thought to confer upon mucins their functional conformation. Membrane-anchored mucins contain a SEA (Sea urchin sperm protein, Enterokinase and Agrin) module, with the exception of MUC4. MUC3A-B, MUC4, MUC11-12, and MUC17 contain two to three epidermal growth factor (EGF)-like domains.

Among the membrane-bound mucins, MUC1 and MUC4 are the two main mucins associated with PC. Although they both belong to the same mucin subfamily, MUC1 and MUC4 present significantly distinct structures. MUC1 has an apparent simple architecture. The MUC1 gene (Figure 1A) codes for a membrane-associated protein with distinct domains: an amino-terminal domain consisting of a 20-amino-acid signal peptide and degenerate tandem repeats; a large central domain (two-thirds of the core protein sequence) made up of variable numbers of a 20 -amino acid repeat; and a carboxyl terminus made of degenerate tandem repeats, a hydrophobic membrane-spanning domain of 31 amino acids, and a cytoplasmic domain of 69 amino acids. In normal individuals, there is a variation in the number of repeats per allele (from 25 to $>125$ repeats), implying that the length of the repetitive array may not be critical for the normal function of MUC1. MUC4, on the other hand, is one of the largest human membrane-anchored mucins identified to date (Figure 1A). The amino-terminus of MUC4 is comprised of a 27-residue signal peptide, followed by three imperfect repetitions of a motif, varying from 126 to 130 residues and by a unique sequence of 554 residues. The central and largest domain is comprised of a perfect tandem repetition of a 16amino-acid residue motif that could be repeated up to 400 times. Over 20 distinct alleles have been identified for MUC4. These show a variation in the size $(6.5-19 \mathrm{~kb})$ of the tandem repeat array. It is not as yet clear whether the size of the tandem repeat is important for the functions or expression of MUC4. The C-terminal region can be divided into 12 domains (CT1 to CT12). CT6, CT7, and CT9 are EGF-like domains, and CT11 corresponds to the transmembrane domain. A putative proteolytic cleavage site (a GDPH motif) is found between domains CT4 and CT5. A MUC4 precursor of $930 \mathrm{kDa}$ yields at least two subunits (MUC4 $\alpha$ and MUC4 $\beta$ ) following proteolytic cleavage. Hence, MUC4 is predicted to be a membrane-associated mucin that extends up to $2.12 \mu \mathrm{m}$ above the cell surface. MUC4 $\alpha$ is an extracellular mucin-type glycoprotein subunit, whereas MUC4 $\beta$ is a growth factor-like transmembrane subunit (Moniaux et al, 1999). Both the MUC1 and MUC4 genes encode numerous alternatively splice forms, some of which are variants devoid of the mucin hallmark, the tandem repeat array. These splice forms, called MUC1/Y, MUC1/X, MUC1/Z, MUC4/X, and MUC4/Y, present a growth factor-like architecture and are thought to be involved in fetal and tumour development. However, the lack of specific antibodies makes it difficult to perform appropriate functional studies.

\section{ABNORMAL EXPRESSION OF MUCIN GENES IN PC}

Of particular interest, the pattern of mucin expression within the pancreas varies depending on the pathophysiologic conditions

A

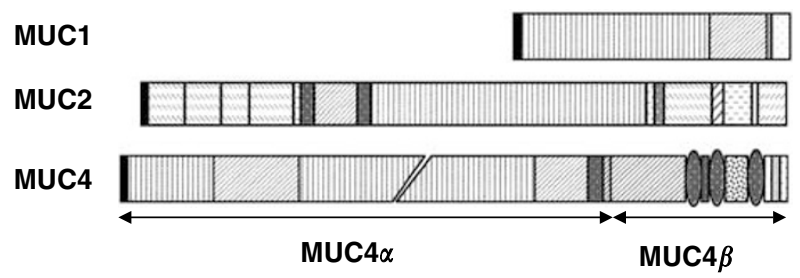

B

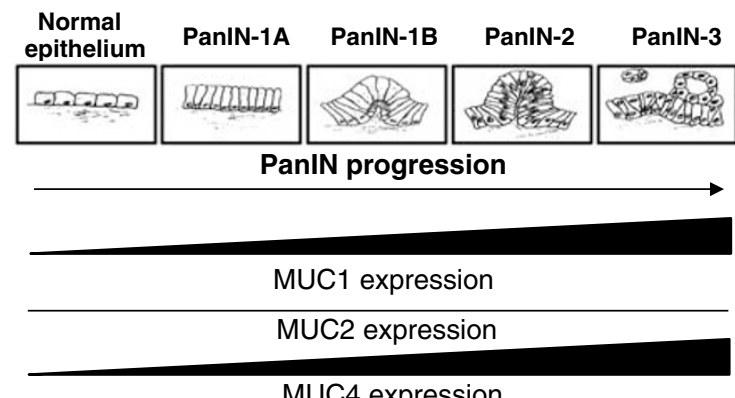

C

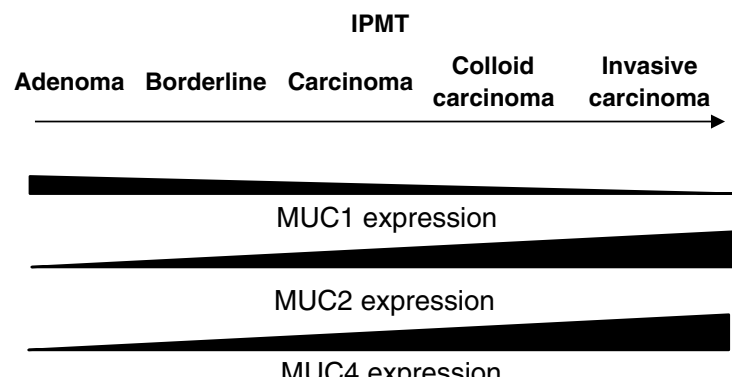

Figure I (A) Schematic representation of the deduced amino-acid sequence of the MUCI, MUC2, and MUC4 genes, which are deregulated in PC. The MUCI apomucin has an apparent simple structure with a central domain composed of sequences repeated in tandem, a transmembrane sequence, and a cytoplasmic tail. MUC4 is a heterodimeric protein, composed of an 850-kDa mucin-type $\alpha$ subunit, noncovalently linked to an $80-\mathrm{kDa}$ growth-factor-like membrane-bound $\beta$ subunit. MUC2 is a secreted mucin with several domains similar to the von Willebrand factor. Keys to figure: black, signal peptide; vertical lines, tandem repeat; diagonal lines serine, threonine-rich nonrepetitive sequence domain; dense dots, domain rich in $\mathrm{N}$-glycosylation sites; open box, unique sequence; hatched boxes, cystein-rich domain; hatched ovals, EGF-like domain; light grey, transmembrane domain; small dots, cytoplasmic tail; descending hatched lines, D domains; ascending hatched lines, CK domain; horizontal lines, C domain; dense vertical lines, B domain. (B) Schematic representation of the PanIN lesions and $\mathrm{MUCl}, 2$, and 4 expression during the progression of PC. Pancreatic intraepithelial neoplasias are thought to mimic the development of PC, evolving from PanIN-IA (flat epithelial lesions composed of tall columnar cells with basally located nuclei) to PanlN-3 (papillary lesion with budding off of small clusters of epithelial cells into the lumen). (C) Expression of MUCI, MUC2, and MUC4 in IPMT. 
Table I Mucin gene expression in different pancreatic physiologic conditions

\begin{tabular}{|c|c|c|c|c|c|c|c|}
\hline Gene & Fetus & Normal pancreas & Pancreatitis & IPMT & PanIN & \multicolumn{2}{|c|}{ Adenocarcinoma } \\
\hline MUC2 & - & - & - & +++ & - & - & $-1++$ \\
\hline MUC3 & - & \pm & \pm & \pm & ND & \pm & $-/+$ \\
\hline MUC4 & - & - & - & $\overline{++}$ & + to +++ & $+\overline{+}+$ & +++ \\
\hline MUC5AC & - & + & $-1+$ & ++ & ND & $-1+$ & $-1+$ \\
\hline MUCII/I2 & ND & $-1+$ & ND & ND & ND & ND & ND \\
\hline $\mathrm{MUCl} 6$ & ND & ND & ND & ND & ND & ++ & ND \\
\hline MUCI7 & ND & ND & ND & ND & ND & ND & + \\
\hline
\end{tabular}

$-=$ negative; $+=$ low; $++=$ moderate; $+++=$ intense; ND = not determined; $-/+=$ from negative to positive depending the sample; $\pm=$ negative or positive depending the reports; IPMT = intraductal papillary-mucinous tumours; Pan $\mathrm{N}=$ pancreatic intraepithelial neoplasias.

(Table 1). The main mucin expressed by the normal pancreatic tissue is MUC6 (Kim et al, 2002). MUC6 and MUC1 are already expressed at an early stage of gestation in the fetal pancreas (Reid and Harris, 1998; Buisine et al, 2000; Adsay et al, 2002). MUC5B is moderately expressed, while MUC1 and MUC5AC are weakly detected in the adult pancreas (Yonezawa et al, 1997; Yonezawa et al, 1999; Andrianifahanana et al, 2001; Terris et al, 2002). We have previously reported that the overexpression of the MUC1 gene as well as the aberrant expression of MUC4 were associated with the development and progression of PC (Swartz et al, 2002; Park et al, 2003). In the normal pancreas, the expression of MUC1 is confined to the apical membrane of the intralobular ductules. It is neither expressed in the larger ducts nor in the islet of langerhans. The overexpression of MUC1 is observed during the early stages of the development of PC, which is further increased in invasive carcinoma (Levi et al, 2004). On the other hand, MUC4 is minimally or not expressed in the normal pancreas or chronic pancreatitis but is highly expressed in human pancreatic tumours and pancreatic tumour cell lines (Balague et al, 1994; Choudhury et al, 2000; Andrianifahanana et al, 2001).

Lesions known as pancreatic intraepithelial neoplasia (PanIN) are thought to represent the early stages of PC development (Figure 1B). They progress from flat to papillary without atypia, to papillary with atypia, and to lesions with severe atypia and are classified PanIN-1A to PanIN-1B, PanIN-2, and PanIN-3 (Hruban et al, 2001). Atypical intraductal lesions can progress to invasive adenocarcinoma (Brat et al, 1998). MUC4 is expressed by metasplastic ducts and its expression increases with a higher grade of PanINs (Swartz et al, 2002; Park et al, 2003). Similarly, MUC1 expression also increases with the progression of PanIN lesions (Figure 1B), whereas MUC2 expression remains unchanged (Adsay et al, 2002).

MUC gene expression has not been extensively studied in intraductal papillary-mucinous tumours (IPMTs) of the pancreas. MUC2 and MUC5AC levels were shown to be very high in IPMT compared to adenocarcinomas (Terada and Nakanuma, 1996; Yonezawa et al, 1997). An altered expression of MUC genes (overexpression of MUC2 and MUC5AC) was seen in IPMTs, which could be correlated with types and lesions (Figure 1C) (Terris et al, 2002). The main difference between adenocarcinoma of the pancreas and IPMT is an increased expression of MUC2 associated with a decreased expression of MUC1 in IPMT $v s$ adenocarcinoma. (Adsay et al, 2002) In both cases, MUC4 is highly aberrantly expressed. While mucin gene profile is in general a good marker for PC, it also serves to distinguish IPMT from adenocarcinoma.

Other mucin genes, such as MUC11 (Williams et al, 1999), MUC12 (Williams et al, 1999), and MUC17 (Gum, Jr et al, 2002) are detected in pancreatic tissues. However, their specific expression pattern in relation to PC development is still unclear.

\section{MUCINS FOR PC DIAGNOSTIC}

The pancreas is the second largest gland of the digestive system following the liver. It lies retroperitoneally in the upper abdominal cavity, with its head enclosed by the curve of the duodenum and its tail reaching to the spleen. It performs both endocrine and exocrine functions. The exocrine component, constituting about $95 \%$ of the mature pancreas, is made up of $85 \%$ acinar cells and $10 \%$ of secreting ductal cells. The endocrine cells are believed to occupy just $1-2 \%$ of the total pancreatic volume in adults.

Adenocarcinomas of the ductal phenotype constitute over $85 \%$ of PC, and other tumours of ductal type, such as mucinous cystic tumours, serous cystic tumours and IPMTs make up another 5$7 \%$. A number of factors, including hereditary, environmental, occupation, and social factors are now recognised as potential contributors to the development of PC (Michaud et al, 2003). Pancreatic cancer is an international problem because of its increasing incidence worldwide. The incidence and age-adjusted mortality rates are almost equal, underscoring the aggressive nature of the disease. It is a daunting challenge for modern medicine as the survival rates for patients diagnosed with metastatic PC range from 4 to 6 months on average. The lethality of the disease is best illustrated by its poor 5-year survival rate of a mere $5 \%$. The highest cure rate only occurs if the tumour is truly localised to the pancreas; however, this stage of disease accounts for fewer than $20 \%$ of all cases. For those patients with localised disease and small tumour size $(<2 \mathrm{~cm})$ with no lymph node metastases and no extension beyond the 'capsule' of the pancreas, complete surgical resection can yield actuarial 5-year survival rates of $18-24 \%$ (Yeo et al, 1997, 1999). Unfortunately, the signs of early stage PC are vague and often attributed to other problems by both patients and physicians. More specific symptoms tend to develop after the tumour has grown to invade other organs or blocked the bile ducts. Patients are usually diagnosed at an advanced stage, with a high incidence of associated metastases, spread all over the body. The inability to diagnose PC at an early, localized, and curable stage has contributed to poor prognosis. The silent course of PC and its explosive fatal outcome have hindered studies of identification of early biochemical and genetic alterations that could help us diagnose the disease at a curable stage and develop successful therapeutic strategies. Thus, PC remains a dismal disease and early diagnostic markers and therapeutic targets are urgently needed.

Early symptoms of PC are difficult to detect and are often ignored. There are no tumour-specific markers for PC; markers such as serum CA 19-9, DUPAN-2, and CA125 that are being used as potential targets have low specificity (McLaughlin et al, 1999; Rhodes, 1999). For over two decades, the structures of these antigens (CA 19-9, DUPAN2, or CA 125) have been heavily 
investigated for the development of serum-based immunoassays to detect early cancers. These antigens contain oligosaccharide structures that are being recognised by monoclonal antibodies. Further, these saccharide epitopes are present on the $\mathrm{O}$-glycosidic chains harboured by the apomucin backbones. For examples, MUC1 carries CA19-9 (Burdick et al, 1997) and DUPAN-2 (Khorrami et al, 2002) epitopes, and MUC16 carries CA 125 epitope (Yin et al, 2002). At this time, CA19-9 remains the only Food and Drug Administration (FDA)-approved marker to monitor PC. The CA 19-9 recognises a mucin-type glycoprotein sialosyl lewis $\mathrm{a} / \mathrm{b}$ antigen. Since $5 \%$ of the general population are lewis $\mathrm{a} / \mathrm{b}$ negative, the maximum sensitivity of this marker is of $95 \%$.

Aberrant glycosylation occurs in essentially all types of experimental and human cancers and has been associated with tumorigenecity and metastasis. In fact, many glycosyl epitopes constitute tumour-associated antigens (TAAs) and have been used as a target for immunotherapy and diagnosis. The nature of aberrant glycosylation as a result or a cause of cancer remains enigmatic. Many recent studies have indicated that some, if not all, types of aberrant glycosylation are a result of initial oncogenic transformation, as well as a key event in induction of invasion and metastasis.

The mucin-type $O$-glycans are attached to the glycoproteins through $\mathrm{O}$-glycosidic linkages between $\mathrm{N}$-acetylgalactosamine and serine or threonine amino-acid residues in the apomucin moieties. $O$-glycans are assembled by a series of reactions catalysed by glycosyltransferases and sulphotransferases in the Golgi compartment. In cancer cells, the expression pattern of these enzymes is dysregulated and leads to tumour-specific glycanic epitopes. Depending on the glycosyltransferases expressed, several hundred different $\mathrm{O}$-glycan structures have been described and classified according to their core structures. All of the cores have the $\mathrm{N}$ acetylgalactosamine linked to the serine or threonine residues that represents the $\mathrm{Tn}$ antigen in common. When sialylated, this antigen forms the sialyl-Tn (sTn) epitope reported to be expressed on the surface of mucin cores. Indeed, sTn is detected at the surface of MUC1 overexpressed by pancreatic adenocarcinoma cells (Burdick et al, 1997). It has been proposed that the appearance of the sTn antigen might result from MUC1 overexpression. The abundance of acceptor sites may saturate the posttranslational modification (Burdick et al, 1997). The sTn antigen is recognised by the mouse monoclonal antibody CC49, which is being extensively investigated for the development of radioimmunotherapeutic protocols.

Alternatively, the Tn antigen can be elongated to form one of the eight distinct cores and terminated with sulphate, sialic acid, fucose, galactose, $\mathrm{N}$-acetylglucosamine, and $\mathrm{N}$-acetylgalactosamine. Depending on the physiologic conditions, the peripheral sugar may vary and gives rise to tumor-associated antigens, such as $\operatorname{Le}^{\mathrm{a}}\left(\right.$ Lewis $\left.^{\mathrm{a}}\right), \mathrm{Le}^{\mathrm{b}}, \mathrm{Le}^{\mathrm{x}}, \mathrm{Le}^{\mathrm{y}}, \mathrm{sLe}^{\mathrm{a}}, \mathrm{sLe}^{\mathrm{c}}$, and $\mathrm{sLe}^{\mathrm{x}}$. The CA 19-9 described previously recognises the sLe ${ }^{a}$ and DUPAN-2 recognises the sLe ${ }^{c}$.

\section{IMPLICATION OF MUCINS IN THE PATHOGENESIS OF PC}

As described previously, both the glycosylation and the expression of mucins are deregulated during the development and progression of pancreatic adenocarcinoma. The main mucins that present the most deregulated expression patterns are MUC1 and MUC4, two mucins that belong to the membrane-anchored mucin subfamily. Therefore, this review will focus on the known functions of MUC1 and MUC4. Both MUC1 and MUC4 play a key role in the development of PC as well as in its progression (invasion and metastasis). As indicated earlier in this paper, the high incidence of metastases in PC is the major cause of its lethality. MUC1 and MUC4 are implicated in almost all of the steps associated with the development of metastases.

MUC1 and MUC4 possess antiadhesive properties. The negative charge of the $\mathrm{O}$-glycosidic chains carried by their central repetitive domain provides a extended conformation to MUC1 and MUC4, with a size up to $500 \mathrm{~nm}$ and $2.12 \mu \mathrm{m}$ (Moniaux et al, 1999), respectively. Moreover, MUC1 and MUC4 are not only upregulated in PC but their upregulation is also accompanied by the loss of their strictly apical localisation. The steric hindrance caused by the overexpression of these two extended glycoproteins disturbs the cell-cell and/or cell-matrix interactions (Komatsu et al, 1997). This physical mechanism favours the release of cancer cells into the circulation. MUC1 also interacts directly with $\beta$-catenin via an SXXXXXSSL motif (where X represents any amino-acid residues) in its cytoplasmic tail (Yamamoto et al, 1997). $\beta$-Catenin plays important functions in the formation of the cell-cell junction via E-cadherin interaction (Hulsken et al, 1994). $\beta$-Catenin also binds to adenomatous polyposis coli (APC) (partner in the Wingless/ Wnt-1 signal pathway). The Wnt-1 intracellular pathway is directly implicated in the development of the central nervous system. Complex binding to $\beta$-catenin is a mutually exclusive process. APC overexpression reduces the level of free cytoplasmic $\beta$-catenin, and thus reduces the formation of $\beta$-catenin/E-cadherin complexes and also decreases intercellular adherence. The formation of these complexes is regulated by the phosphorylation of the cytoplamic tail of each partner by GSK3 $\beta$. After phosphorylation, $\beta$-catenin is degraded. GSK3 $\beta$ is also able to phosphorylate the $\beta$-cateninbinding site on the MUC1 cytoplasmic tail (Li et al, 1998). The phosphorylation at the serine residue of the cytoplasmic tail of MUC1 by GSK $3 \beta$ was shown to decrease the binding of MUC1 to $\beta$ catenin (Li et al, 1998). The relative level of MUC1, E-cadherin, $\beta$ catenin, GSK3 $\beta$, and APC seem to be critical for maintaining epithelium integrity. The overexpression of MUC1 leads to an increase in the interaction between MUC1 and $\beta$-catenin, thereby inhibiting $\beta$-catenin/E-cadherin interaction and disrupting cellcell contacts, which facilitate the release of the tumour cell from the tissue. The cytoplasmic tail of MUC1 is also phosphorylated at tyrosine residue. In vitro, tyrosine phosphorylation of the MUC1 cytoplasmic domain increases recolonisation and promotes changes in cell-cell adhesion (Quin and McGuckin, 2000). Interestingly, both src and EGFR induce tyrosine phosphorylation and enhance interactions between MUC1 and $\beta$-catenin (Li et al, 2001; Schroeder et al, 2001).

The expression of mucin-associated carbohydrate antigens, sLe $\mathrm{e}^{\mathrm{x}}$ and sTn, is associated with higher-grade PanIN lesions (Park et al, 2003) and is thought to result from a shift in the expression of glycosyltransferases. These mucin-associated antigens are known to bind endothelial cells through the P- and E-selectins, and the cell-adhesion molecule, ICAM-1 (Regimbald et al, 1996). The Pselectin ligand (PSGL-1) (Sako et al, 1993) presents a structure similar to MUC1 and MUC4 and carries within its repetitive domain $\mathrm{O}$-glycosidic chains with terminal sugars comparable to those of MUC1 and MUC4 in tumoral situations. Therefore, in addition to favouring the release of PC cells, MUC1 and MUC4 also facilitate their extravasation into and/or from the circulation (Burdick et al, 1997). MUC4 is known to inhibit tumour killing by lymphokine-activated killer cells (Komatsu et al, 1999).

Information regarding the role of MUC1 and MUC4 in the growth of primary pancreatic tumours has remained scarce until recently. Both mucins have been reported to serve as potential modulators of the receptor tyrosine kinase signalling pathways. Indeed, both MUC1 and MUC4 have been referred to as the heterodimeric partners of EGFR/HER1 (Li et al, 2001; Schroeder et al, 2001) and HER2 (Carraway et al, 2002), respectively. When MUC1 interacts with EGFR, the cytoplasmic tail of MUC1 becomes phosphorylated and leads to the activation of c-Src (Li et al, 2001). Moreover, the formation of the complex activates the mitogenic MAP kinase pathway (Schroeder et al, 2001). For MUC4, its 
membrane-bound subunit acts as a ligand for HER2, activating this growth factor receptor, and in synergy with neuregulin, potentiates the phopshorylation of HER2 and HER3. Phosphorylation of HER 2 occurs at residue Tyr1248 after binding with MUC4 and leads to the upregulation of the cell-cycle inhibitor, p2 $7^{\text {kip }}$ (Jepson et al, 2002). However, in presence of neuregulin, MUC4/ HER2 activation downregulates $\mathrm{p} 27^{\mathrm{kip}}$ but activates the protein kinase B/Akt via HER3. Therefore, MUC4 appears to be a modulator of cell proliferation. Inhibition of MUC4 expression using antisense or short-interfering RNA (siRNA) oligonucleotides specific to MUC4 results in a decreased tumorigenicity and dissemination of cancer cells (Singh et al, 2004). We believe that MUC4 is implicated in tumour growth and metastasis by directly altering the tumour cell properties (adhesion/aggregation and motility), and/or in part, via modulating HER2 expression.

\section{CONCLUSIONS AND PERSPECTIVES}

Pancreatic cancer is an international problem because of its increasing incidence worldwide. The incidence and age-adjusted mortality rates are almost equal, underscoring the aggressive nature of the disease. Although efforts are being made to unveil the principles governing the initiation and progression of this cancer, and to identify the factors that confer its particular aggressiveness, the exact succession of molecular events underlying the development of this devastating malignancy has remained unsolved. The management of PC is, therefore, an ongoing challenge. Mucins have been implicated in the pathogenesis and progression of PC. Differential glycosylation, aberrant expression, and alternative splicing of mucins are being investigated in PC. MUC1 and MUC4 are finding unique functions in the early diagnosis and progression of the disease. The potential use of these mucins in the targeted therapy of pancreatic and other cancers is under active investigation.

\section{ACKNOWLEDGEMENTS}

Ms Kristi LW Berger, Eppley Institute, is greatly acknowledged for editorial assistance. The authors of this article were supported by a grant from the National Institutes of Health (RO1 CA78590).

\section{REFERENCES}

Adsay NV, Merati K, Andea A, Sarkar F, Hruban RH, Wilentz RE, Goggins M, Iocobuzio-Donahue C, Longnecker DS, Klimstra DS (2002) The dichotomy in the preinvasive neoplasia to invasive carcinoma sequence in the pancreas: differential expression of MUC1 and MUC2 supports the existence of two separate pathways of carcinogenesis. Mod Pathol 15: $1087-1095$

Andrianifahanana M, Moniaux N, Schmied BM, Ringel J, Friess H, Hollingsworth MA, Buchler MW, Aubert JP, Batra SK (2001) Mucin (MUC) gene expression in human pancreatic adenocarcinoma and chronic pancreatitis: a potential role of MUC4 as a tumor marker of diagnostic significance. Clin Cancer Res 7: 4033-4040

Andrianifahanana M, Moniaux N, Batra SK (2004) Pathophysiological perspectives of pancreatic mucins. In Toxicology of the Pancreas Biology, Pathophysiology, Etiology and Molecular Biology of Pancreatic Injury Pour P (ed) London, UK: Taylor \& Francis, In press

Balague C, Gambus G, Carrato C, Porchet N, Aubert JP, Kim YS, Real FX (1994) Altered expression of MUC2, MUC4, and MUC5 mucin genes in pancreas tissues and cancer cell lines. Gastroenterology 106: $1054-1061$

Braga VM, Pemberton LF, Duhig T, Gendler SJ (1992) Spatial and temporal expression of an epithelial mucin, Muc-1, during mouse development. Development 115: $427-437$

Brat DJ, Lillemoe KD, Yeo CJ, Warfield PB, Hruban RH (1998) Progression of pancreatic intraductal neoplasias to infiltrating adenocarcinoma of the pancreas. Am J Surg Pathol 22: $163-169$

Buisine MP, Devisme L, Degand P, Dieu MC, Gosselin B, Copin MC, Aubert JP, Porchet N (2000) Developmental mucin gene expression in the gastroduodenal tract and accessory digestive glands. II. Duodenum and liver, gallbladder, and pancreas. J Histochem Cytochem 48: $1667-1676$

Burdick MD, Harris A, Reid CJ, Iwamura T, Hollingsworth MA (1997) Oligosaccharides expressed on MUC1 produced by pancreatic and colon tumor cell lines. I Biol Chem 272: 24198-24202

Carraway KL, Perez A, Idris N, Jepson S, Arango M, Komatsu M, Haq B, Price-Schiavi SA, Zhang J, Carraway CA (2002) Muc4/sialomucin complex, the intramembrane ErbB2 ligand, in cancer and epithelia: to protect and to survive. Prog Nucleic Acid Res Mol Biol 71: 149-185

Choudhury A, Moniaux N, Winpenny JP, Hollingsworth MA, Aubert JP, Batra SK (2000) Human MUC4 mucin cDNA and its variants in pancreatic carcinoma. J Biochem (Tokyo) 128: 233-243

Gum Jr JR, Crawley SC, Hicks JW, Szymkowski DE, Kim YS (2002) MUC17, a novel membrane-tethered mucin. Biochem Biophys Res Commun 291: $466-475$

Hollingsworth MA, Swanson BJ (2004) Mucins in cancer: protection and control of the cell surface. Nat Rev Cancer 4: 45-60

Hruban RH, Adsay NV, Albores-Saavedra J, Compton C, Garrett ES, Goodman SN, Kern SE, Klimstra DS, Kloppel G, Longnecker DS,
Luttges J, Offerhaus GJ (2001) Pancreatic intraepithelial neoplasia: a new nomenclature and classification system for pancreatic duct lesions. Am J Surg Pathol 25: 579-586

Hulsken J, Behrens J, Birchmeier W (1994) Tumor-suppressor gene products in cell contacts: the cadherin-APC-armadillo connection. Curr Opin Cell Biol 6: $711-716$

Jepson S, Komatsu M, Haq B, Arango ME, Huang D, Carraway CA, Carraway KL (2002) Muc4/sialomucin complex, the intramembrane ErbB2 ligand, induces specific phosphorylation of ErbB2 and enhances expression of p27(kip), but does not activate mitogen-activated kinase or protein kinaseB/Akt pathways. Oncogene 21: 7524-7532

Khorrami AM, Choudhury A, Andrianifahanana M, Varshney GC, Bhattacharyya SN, Hollingsworth MA, Kaufman B, Batra SK (2002) Purification and characterization of a human pancreatic adenocarcinoma mucin. J Biochem (Tokyo) 131: 21 - 29

Kim GE, Bae HI, Park HU, Kuan SF, Crawley SC, Ho JJ, Kim YS (2002) Aberrant expression of MUC5AC and MUC6 gastric mucins and sialyl Tn antigen in intraepithelial neoplasms of the pancreas. Gastroenterology 123: $1052-1060$

Komatsu M, Carraway CA, Fregien NL, Carraway KL (1997) Reversible disruption of cell - matrix and cell - cell interactions by overexpression of sialomucin complex. J Biol Chem 272: 33245 -33254

Komatsu M, Yee L, Carraway KL (1999) Overexpression of sialomucin complex, a rat homologue of MUC4, inhibits tumor killing by lymphokine-activated killer cells. Cancer Res 59: 2229-2236

Levi E, Klimstra DS, Adsay NV, Andea A, Basturk O (2004) MUC1 and MUC2 in pancreatic neoplasia. J Clin Pathol 57: 456-462

Li Y, Bharti A, Chen D, Gong J, Kufe D (1998) Interaction of glycogen synthase kinase 3beta with the DF3/MUC1 carcinoma-associated antigen and beta-catenin. Mol Cell Biol 18: 7216-7224

Li Y, Ren J, Yu W, Li Q, Kuwahara H, Yin L, Carraway III KL, Kufe D (2001) The epidermal growth factor receptor regulates interaction of the human DF3/MUC1 carcinoma antigen with c-Src and beta-catenin. J Biol Chem 276: $35239-35242$

McLaughlin R, O'Hanlon D, Kerin M, Kenny P, Grimes H, Given HF (1999) Are elevated levels of the tumor marker CA19-9 of any clinical significance?-an evaluation. Ir J Med Sci 168: 124-126

Michaud DS, Giovannucci E, Willett WC, Colditz GA, Fuchs CS (2003) Dietary meat, dairy products, fat, and cholesterol and pancreatic cancer risk in a prospective study. Am J Epidemiol 157: 1115-1125

Moniaux N, Escande F, Batra SK, Porchet N, Laine A, Aubert JP (2000) Alternative splicing generates a family of putative secreted and membrane-associated MUC4 mucins. Eur $J$ Biochem 267: $4536-4544$

Moniaux N, Escande F, Porchet N, Aubert JP, Batra SK (2001) Structural organization and classification of the human mucin genes. Front Biosci 6: D1192 - D1206 
Moniaux N, Nollet S, Porchet N, Degand P, Laine A, Aubert JP (1999) Complete sequence of the human mucin MUC4: a putative cell membrane-associated mucin. Biochem J 338: 325-333

Park HU, Kim JW, Kim GE, Bae HI, Crawley SC, Yang SC, Gum Jr J, Batra SK, Rousseau K, Swallow DM, Sleisenger MH, Kim YS (2003) Aberrant expression of MUC3 and MUC4 membrane-associated mucins and sialyl lex antigen in pancreatic intraepithelial neoplasia. Pancreas 26: $48-54$

Quin RJ, McGuckin MA (2000) Phosphorylation of the cytoplasmic domain of the MUC1 mucin correlates with changes in cell-cell adhesion. Int J Cancer 87: 499-506

Regimbald LH, Pilarski LM, Longenecker BM, Reddish MA, Zimmermann G, Hugh JC (1996) The breast mucin MUCI as a novel adhesion ligand for endothelial intercellular adhesion molecule 1 in breast cancer. Cancer Res 56: $4244-4249$

Reid CJ, Harris A (1998) Developmental expression of mucin genes in the human gastrointestinal system. Gut 42: 220-226

Reis CA, David L, Correa P, Carneiro F, de Bolos C, Garcia E, Mandel U, Clausen H, Sobrinho-Simoes M (1999) Intestinal metaplasia of human stomach displays distinct patterns of mucin (MUC1, MUC2, MUC5AC, and MUC6) expression. Cancer Res 59: $1003-1007$

Rhodes JM (1999) Usefulness of novel tumor markers. Ann Oncol 10: $118-121$

Sako D, Chang XJ, Barone KM, Vachino G, White HM, Shaw G, Veldman GM, Bean KM, Ahern TJ, Furie B (1993) Expression cloning of a functional glycoprotein ligand for P-selectin. Cell 75: $1179-1186$

Schroeder JA, Thompson MC, Gardner MM, Gendler SJ (2001) Transgenic MUC1 interacts with epidermal growth factor receptor and correlates with mitogen-activated protein kinase activation in the mouse mammary gland. J Biol Chem 276: $13057-13064$

Singh AP, Moniaux N, chauhan SC, Meza JL, Batra SK (2004) Inhibition of MUC4 expression suppresses pancreatic tumor cell growth and metastasis. Cancer Res 64: 622-630

Swartz MJ, Batra SK, Varshney GC, Hollingsworth MA, Yeo CJ, Cameron JL, Willentz RE, Hruban RH, Argani P (2002) MUC4 expression increases progressively in pancreatic intraepithelial neoplasia (PanIN). Am J Clin Pathol 117: 791 - 796

Terada T, Nakanuma Y (1996) Expression of mucin carbohydrate antigens ( $\mathrm{T}$, Tn and sialyl Tn) and MUC-1 gene product in intraductal papillarymucinous neoplasm of the pancreas. Am J Clin Pathol 105: 613-620
Terris B, Dubois S, Buisine MP, Sauvanet A, Ruszniewski P, Aubert JP, Porchet N, Couvelard A, Degott C, Flejou JF (2002) Mucin gene expression in intraductal papillary-mucinous pancreatic tumors and related lesions. J Pathol 197: 632-637

Van Klinken BJ, Einerhand AW, Buller HA, Dekker J (1998) The oligomerization of a family of four genetically clustered human gastrointestinal mucins. Glycobiology 8: 67-75

Williams SJ, McGuckin MA, Gotley DC, Eyre HJ, Sutherland GR, Antalis TM (1999) Two novel mucin genes down-regulated in colorectal cancer identified by differential display. Cancer Res 59: 4083-4089

Wreschner DH, Hareuveni M, Tsarfaty I, Smorodinsky N, Horev J, Zaretsky J, Kotkes P, Weiss M, Lathe R, Dion A (1990) Human epithelial tumor antigen cDNA sequences. Differential splicing may generate multiple protein forms. Eur J Biochem 189: 463-473

Yamamoto M, Bharti A, Li Y, Kufe D (1997) Interaction of the DF3/MUC1 breast carcinoma-associated antigen and beta-catenin in cell adhesion. J Biol Chem 272: $12492-12494$

Yeo CJ, Abrams RA, Grochow LB, Sohn TA, Ord SE, Hruban RH, Zahurak ML, Dooley WC, Coleman J, Sauter PK, Pitt HA, Lillemoe KD, Cameron JL (1997) Pancreaticoduodenectomy for pancreatic adenocarcinoma: postoperative adjuvant chemoradiation improves survival. A prospective, single-institution experience. Ann Surg 225: $621-633$

Yeo CJ, Cameron JL, Sohn TA, Coleman J, Sauter PK, Hruban RH, Pitt HA, Lillemoe KD (1999) Pancreaticoduodenectomy with or without extended retroperitoneal lymphadenectomy for periampullary adenocarcinoma: comparison of morbidity and mortality and short-term outcome. Ann Surg 229: $613-622$

Yin BW, Dnistrian A, Lloyd KO (2002) Ovarian cancer antigen CA125 is encoded by the MUC16 mucin gene. Int J Cancer 98: 737-740

Yonezawa S, Horinouchi M, Osako M, Kubo M, Takao S, Arimura Y, Nagata K, Tanaka S, Sakoda K, Aikou T, Sato E (1999) Gene expression of gastric type mucin (MUC5AC) in pancreatic tumors: its relationship with the biological behavior of the tumor. Pathol Int 49: 45-54

Yonezawa S, Sueyoshi K, Nomoto M, Kitamura H, Nagata K, Arimura Y, Tanaka S, Hollingsworth MA, Siddiki B, Kim YS, Sato E (1997) MUC2 gene expression is found in noninvasive tumors but not in invasive tumors of the pancreas and liver: its close relationship with prognosis of the patients. Hum Pathol 28: 344-352 